\title{
Syrinx regression after correction of iatrogenic kyphotic deformity: illustrative case
}

\author{
Robert Y. North, MD, PhD, Timothy J. Yee, MD, Michael J. Strong, MD, PhD, Yamaan S. Saadeh, MD, Hugh J. L. Garton, MD, and \\ Paul Park, MD
}

Department of Neurosurgery, University of Michigan, Ann Arbor, Michigan

BACKGROUND Syringomyelia has a long-established association with pediatric scoliosis, but few data exist on the relationship of syringomyelia to pediatric kyphotic deformities.

OBSERVATIONS This report reviewed a unique case of rapid and sustained regression of syringomyelia in a 13-year-old girl after surgical correction of iatrogenic kyphotic deformity.

LESSONS In cases of syringomyelia associated with acquired spinal deformity, treatment of deformity to resolve an associated subarachnoid block should be considered because it may obviate the need for direct treatment of syrinx.

https://thejns.org/doi/abs/10.3171/CASE21483

KEYWORDS postlaminectomy kyphosis; scoliosis; spinal deformity; syringomyelia; syrinx

Syringomyelia has a long-established association with spinal deformity ${ }^{1-3}$ and is often described in relation to scoliosis. The concurrent presence of a syrinx and kyphotic spinal deformity is less often encountered. ${ }^{4-10}$ Here we present a unique pediatric case of an enlarging syrinx at the site of prior spinal cord tumor resection. Although initially thought to be associated with the tumor, the syrinx was ultimately found to be secondary to the development of an iatrogenic, kyphotic spinal deformity. Correction of the deformity resulted in rapid and sustained regression of the syrinx. This case supports the supposition that acquired spinal deformity can contribute to syrinx formation, and in such cases, deformity correction alone may sufficiently treat both spinal deformity and the syrinx., ${ }^{4-11}$

\section{Illustrative Case}

\section{History, Physical Examination, and Initial Imaging Findings}

A 13-year-old girl with remote history of cervicothoracic anaplastic oligodendroglioma who was previously treated with multiple resections (including a C4-T4 laminectomy), adjuvant radiotherapy, and C3-L1 posterior fusion for postlaminectomy kyphosis by an outside spinal surgeon was referred to the adult spine clinic with recurrent hardware failure.
The patient was a thin (body mass index 19) but normally developed girl with a pronounced cervicothoracic kyphosis. Her neurological examination revealed mild left leg weakness, altered sensation in left arm and leg, and left lower extremity hyperreflexia. These deficits were reported as longstanding and stable. Magnetic resonance imaging (MRI) (Fig. 1) and radiographs (Fig. 2) show the patient after previous spinal fusion (Figs. $1 \mathrm{~A}$ and $2 \mathrm{~A}$ ) performed elsewhere. At presentation to our department, MRI and radiographs revealed prominent cervicothoracic kyphosis $\left(108^{\circ}\right)$ due to hardware failure with the apex at T3-T4 and an enlarging cervicothoracic syrinx with concern for tumor recurrence (Figs. 1B and 2B; postcontrast MRI not shown). Supine imaging and flexion/extension radiographs indicated minimal correction of the kyphosis. Computed tomography revealed a posterolateral bony fusion from $\mathrm{C} 3$ to $\mathrm{T} 3$ and $\mathrm{T} 4$ to $\mathrm{L} 1$ with pseudarthrosis at T3-T4.

\section{Operative Details}

The patient was in a prone position on a flat-top surgical table and was supported with gel rolls. Her head was secured with Mayfield attachment. Multimodal neuromonitoring was used. After exposure, inspection revealed solid and confluent posterolateral fusion masses from C3 to C7 and T6 to L1. Three-dimensional navigation was used to place lateral mass screws at $\mathrm{C} 3-\mathrm{C} 6$ and pedicle screws at T2, T3,

ABBREVIATIONS CSF = cerebrospinal fluid; MRI = magnetic resonance imaging; POD = postoperative day

INCLUDE WHEN CITING Published January 3, 2022; DOI: 10.3171/CASE21483.

SUBMITTED August 26, 2021. ACCEPTED October 22, 2021.

(C) 2022 The authors, CC BY-NC-ND 4.0 (http://creativecommons.org/licenses/by-nc-nd/4.0/). 

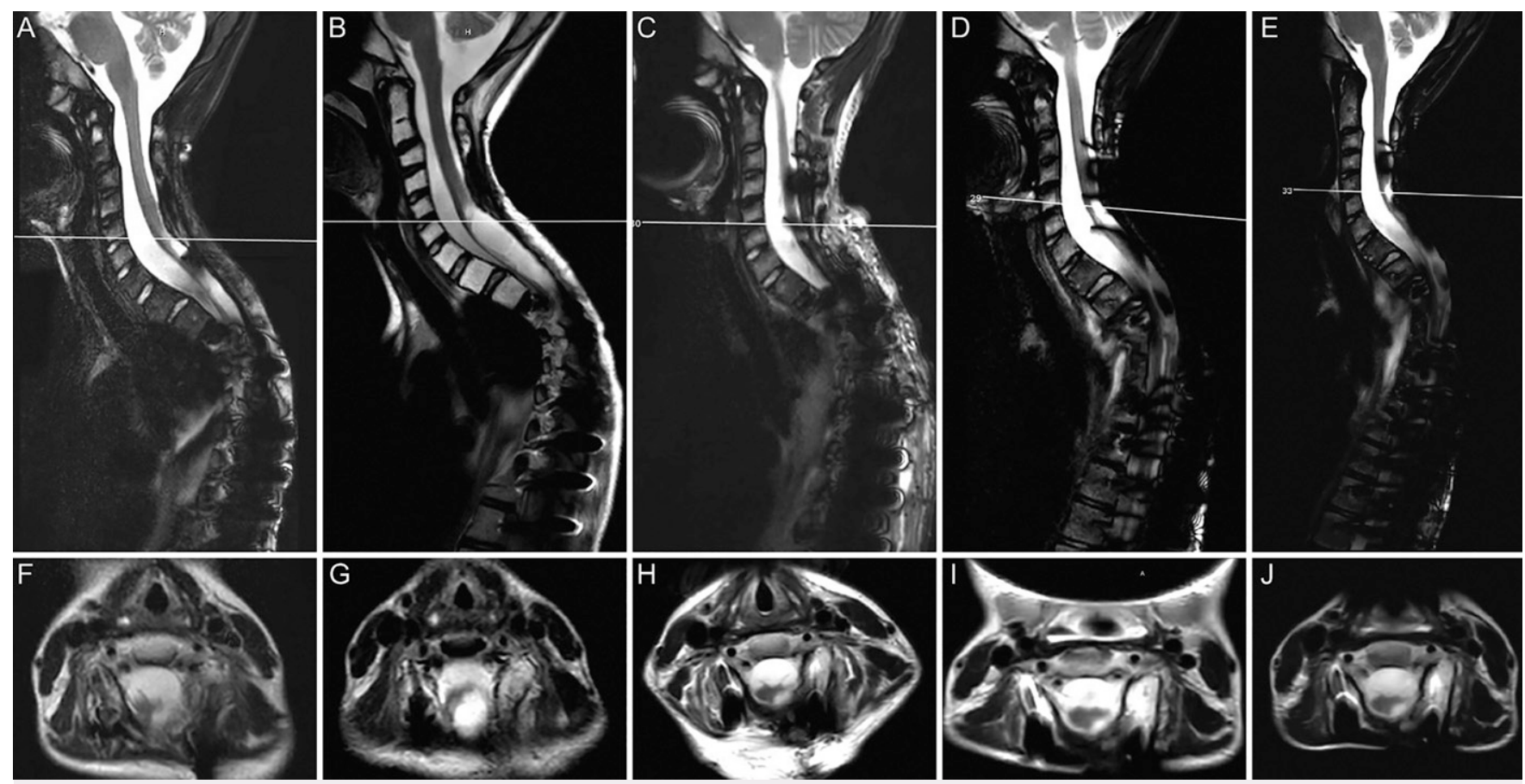

FIG. 1. Sagittal and axial T2-weighted MRI. A and F: After initial spinal fusion. B and G: After pseudarthrosis, instrumentation failure, and worsening of deformity. C and H: Postoperative day 1 after revision deformity correction. D and I: Postoperative 6-month follow-up. E and J: Postoperative 15-month follow-up.

and T5. Existing thoracic pedicle screws were retained. An extended T4 pedicle subtraction osteotomy, including T3-T4 discectomy and Smith-Peterson osteotomies at T2-T3 and T7-T8, was performed. After the wedge osteotomy was created, the Mayfield bed attachment was loosened and the patient's head was translated dorsally to close the osteotomy. Neuromonitoring was without changes after osteotomy closure, and fluoroscopy was used to examine sagittal and coronal alignment. Plastic surgery was performed to create bilateral paraspinous advancement flaps for closure to complete the operation.

\section{Postoperative Course and Imaging}

After surgery, the patient was neurologically unchanged from baseline. MRI and full-spine radiographs on postoperative day (POD) 1 demonstrated significant improvement in alignment (tho racic kyphosis $67^{\circ}$ ) and marked regression of cervicothoracic syrinx (Figs. $1 \mathrm{C}$ and $2 \mathrm{C}$ ). The patient was discharged home on POD 3. At discharge, the patient was neurologically unchanged from baseline, ambulated without assistance, and reported minimal pain. At 3-month follow-up, the patient had improvement in
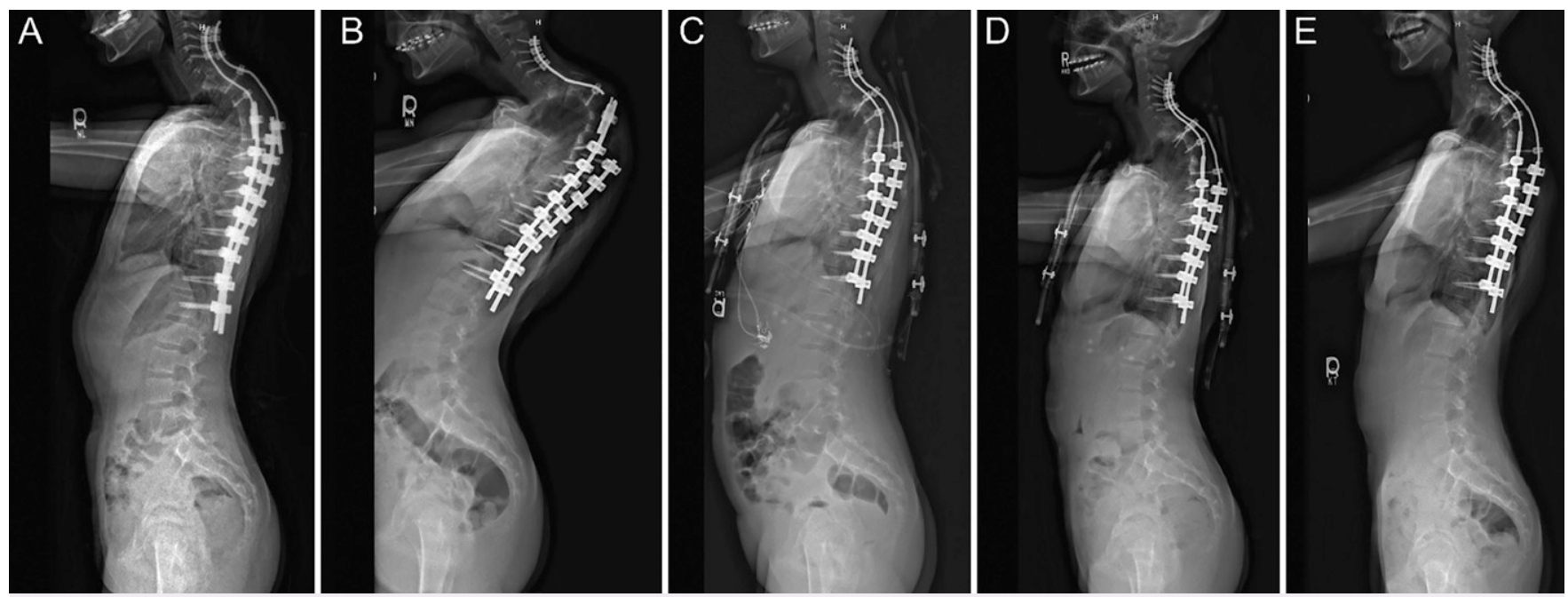

FIG. 2. Standing lateral spine radiographs. A: After initial spinal fusion. B: After pseudarthrosis, instrumentation failure, and worsening of deformity. C: Postoperative day 1 after revision deformity correction. D: Postoperative 3-month follow-up. E: Postoperative 15-month follow-up. 
her left leg strength compared to preoperative "baseline," surgical incisions were well healed, and she reported 0/10 pain level. Full-spine radiographs at 3-month follow-up revealed sustained correction of alignment with $66^{\circ}$ of thoracic kyphosis (Fig. 2D). Six-month follow-up MRI demonstrated stable regression of cervicothoracic syrinx (Fig. 1D). At 15-month follow-up, she reported improvement in left leg numbness, and her hypersensitivity improved. MRI demonstrated stable regression of the cervicothoracic syrinx (Fig. 1E), and upright radiographs demonstrated stable improvement of alignment without evidence of hardware failure (Fig. 2E).

\section{Discussion \\ Observations}

In this case, indications for surgical intervention included significant functional limitations, relative spinal instability due to partial removal of hardware, and the enlarging syrinx. The patient's skeletal maturity (Risser 5), good neurological function, and reported favorable oncological prognosis all supported surgical treatment. Preoperative imaging suggested a relatively rigid deformity, given minimal change in cervicothoracic deformity. Imaging was obtained with patient in supine position using flexion-extension radiographs or imaging in halo-gravity traction. Given the rigidity and extent of the deformity, which needed $>30^{\circ}$ of sagittal correction, Schwab grade 3 or 4 osteotomy was deemed necessary. ${ }^{12-16}$ Although theoretical estimates for sagittal correction with T4 pedicle subtraction are as high as $37.2^{\circ},{ }^{17}$ clinical series indicate that average correction is closer to $20^{\circ}$ to $25^{\circ}$. $^{15,18,19}$ Given these estimates, additional Schwab grade 1 osteotomies were planned and proved necessary.

The etiology of syrinx formation is still unclear but is thought to be caused by disturbance in normal cerebrospinal fluid (CSF) flow dynamics. $^{20}$ For example, in Chiari I malformation, the downward herniation of the cerebellar tonsils obstructs normal CSF flow, thus resulting in an accumulation of fluid in either the central canal or spinal cord parenchyma. ${ }^{20} \mathrm{~A}$ similar mechanism is thought to occur in other pathologies, including extramedullary lesions, infection, and trauma. ${ }^{20}$ Tensile radial stress in the spinal cord caused by tethering is another common theory for the formation of a syrinx. ${ }^{21,22}$ In addition to the mechanical effects of cord tethering, metabolic and ischemic changes have also been proposed as contributing factors for the formation of a syrinx in animal models. ${ }^{23,24}$

Regarding the syrinx in our case, our initial consideration was syrinx shunting in conjunction with deformity correction. However, when considering the temporal association of syrinx enlargement with loss of deformity correction (Figs. 1A, 1F, and 2A versus Figs. $1 \mathrm{~B}, 1 \mathrm{G}$, and $2 \mathrm{~B}$ ), it was thought plausible that blockage of CSF flow by the kyphotic deformity contributed to the syrinx formation and that treatment of the deformity may lead to syrinx stabilization or regression.

\section{Lessons}

In cases of syringomyelia associated with acquired spinal deformity, treatment of deformity to resolve an associated subarachnoid block should be considered because it may obviate the need for direct treatment of syrinx.

\section{References}

1. Huebert HT, MacKinnon WB. Syringomyelia and scoliosis. J Bone Joint Surg Br. 1969;51(2):338-343.

2. Strahle J, Smith BW, Martinez M, et al. The association between Chiari malformation Type I, spinal syrinx, and scoliosis. J Neurosurg Pediatr. 2015;15(6):607-611.

3. Woods WW, Pimenta AM. Intramedullary lesions of the spinal cord. Arch Neurol Psychiatry. 1944;52(5):383-399.

4. Abel R, Gerner HJ, Smit C, Meiners T. Residual deformity of the spinal canal in patients with traumatic paraplegia and secondary changes of the spinal cord. Spinal Cord. 1999;37(1):14-19.

5. Allen SS, Kahn EA. A case of scoliosis produced by spinal cord tumor. J Nerv Ment Dis. 1933;77(1):53-55.

6. Batzdorf U. Primary spinal syringomyelia: a personal perspective. Neurosurg Focus. 2000;8(3):E7.

7. Batzdorf U, Khoo LT, McArthur DL. Observations on spine deformity and syringomyelia. Neurosurgery. 2007;61(2):370-377.

8. Citron N, Edgar MA, Sheehy J, Thomas DG. Intramedullary spinal cord tumours presenting as scoliosis. J Bone Joint Surg Br. 1984;66(4):513-517.

9. Goel A, Desai K. Surgery for syringomyelia: an analysis based on 163 surgical cases. Acta Neurochir (Wien). 2000;142(3):293-302.

10. Schurch B, Wichmann W, Rossier AB. Post-traumatic syringomyelia (cystic myelopathy): a prospective study of 449 patients with spinal cord injury. J Neurol Neurosurg Psychiatry. 1996;60(1):61-67.

11. Wang Y, Xie J, Zhao Z, Zhang Y, Li T, Si Y. Changes in CSF flow after one-stage posterior vertebral column resection in scoliosis patients with syringomyelia and Chiari malformation type I. J Neurosurg Spine. 2013;18(5):456-464.

12. Bridwell KH, Lewis SJ, Lenke LG, Baldus C, Blanke K. Pedicle subtraction osteotomy for the treatment of fixed sagittal imbalance. J Bone Joint Surg Am. 2003;85(3):454-463.

13. Faundez A, Byrne F, Sylvestre C, Lafage V, Cogniet A, Le Huec JC. Pedicle subtraction osteotomy in the thoracic spine and thoracolumbar junction: a retrospective series of 28 cases. Eur Spine J. 2015;24(suppl 1):S42-S48.

14. O'Shaughnessy BA, Kuklo TR, Hsieh PC, Yang BP, Koski TR, Ondra SL. Thoracic pedicle subtraction osteotomy for fixed sagittal spinal deformity. Spine (Phila Pa 1976). 2009;34(26):2893-2899.

15. Obeid I, Diebo BG, Boissiere L, et al. Single level proximal thoracic pedicle subtraction osteotomy for fixed hyperkyphotic deformity: surgical technique and patient series. Oper Neurosurg (Hagerstown). 2018;14(5):515-523.

16. Schwab F, Blondel B, Chay E, et al. The comprehensive anatomical spinal osteotomy classification. Neurosurgery. 2014;74(1):112-120.

17. Hayashi $Y$, Kushida K, Kitazawa A, et al. Measurement of vertebral body dimensions of the thoracic and lumbar spines of 242 healthy women. J Bone Miner Metab. 1998;16:27-33.

18. Lewis SJ, Goldstein S, Bodrogi A, et al. Comparison of pedicle subtraction and Smith-Petersen osteotomies in correcting thoracic kyphosis when closed with a central hook-rod construct. Spine (Phila Pa 1976). 2014;39(15):1217-1224.

19. Zeng Y, Chen Z, Guo Z, Qi Q, Li W, Sun C. The posterior surgical treatment for focal kyphosis in upper-middle thoracic spine. Eur Spine J. 2014;23(11):2291-2298.

20. Vandertop WP. Syringomyelia. Neuropediatrics. 2014;45(1):3-9.

21. Bertram CD, Bilston LE, Stoodley MA. Tensile radial stress in the spinal cord related to arachnoiditis or tethering: a numerical model. Med Biol Eng Comput. 2008;46(7):701-707.

22. Tsitouras V, Sgouros S. Syringomyelia and tethered cord in children. Childs Nerv Syst. 2013;29(9):1625-1634. 
23. Kang JK, Kim MC, Kim DS, Song JU. Effects of tethering on regional spinal cord blood flow and sensory-evoked potentials in growing cats. Childs Nerv Syst. 1987;3(1):35-39.

24. Tani S, Yamada S, Knighton RS. Extensibility of the lumbar and sacral cord. Pathophysiology of the tethered spinal cord in cats. $J$ Neurosurg. 1987;66(1):116-123.

\section{Disclosures}

Dr. Park is a consultant for Globus, NuVasive, Depuy Synthes, receives royalties from Globus and is involved in non-study related research funded by ISSG, Depuy Synthes, Cerapedics, SI Bone.

\section{Author Contributions}

Conception and design: Park, North, Saadeh, Garton. Acquisition of data: Park, North, Strong, Garton. Analysis and interpretation of data: Park, North, Strong. Drafting the article: North, Yee, Strong, Saadeh. Critically revising the article: Park, North, Yee, Saadeh. Reviewed submitted version of manuscript: Park, North, Saadeh, Garton. Approved the final version of the manuscript on behalf of all authors: Park. Study supervision: Park.

\section{Correspondence}

Paul Park: University of Michigan, Ann Arbor, Ml. ppark@med.umich. edu. 